\title{
Reorientación del gran capital hacia lo inmobiliario
}

Samuel Jaramillo

Centro de Estudios de Desarrollo Económico CEDE. Universidad de los Andes. Bogotá, Colombia.

Recibido: 5 de septiembre de 2020. Aceptado: 20 de octubre de 2020.

\begin{abstract}
Resumen
¿Por qué la producción inmobiliaria, que fue una rama relativamente secundaria de la acumulación de capital, atrasada en términos técnicos y empresariales, en épocas recientes se ha convertido en una opción de inversión muy importante para el gran capital? En una etapa de debilidad en la tasa de ganancia y de escasez de negocios redituables, ¿qué atractivo ofrece lo inmobiliario para los grandes inversionistas? En América Latina, donde esta actividad tenía un alcance nacional, e incluso regional o local, limitado de repente ve llegar masivamente capitales multinacionales: ¿cómo obtienen remuneraciones que expliquen esta mutación? El trabajo se propone dar luz sobre el tema, partiendo de la hipótesis de que en el mercado del suelo urbano aquello se logra a través de la especulación. Una expresión que suele ser imprecisa, con significados muy diversos y a veces contradictorios. Con base en la Teoría Marxista de la Renta del Suelo Urbano desarrollada por el autor, la categoría clave para examinar estas operaciones será la de especulación inductiva, que no tiene la apariencia de especulación, pero en la cual los inversionistas le apuestan a combinar la ganancia propiamente capitalista con la captura de incrementos en el precio del suelo urbano. En estas operaciones el gran tamaño de la acumulación de capital es decisiva, así como el apoyo del Estado, lo que es funcional a las políticas urbanas neoliberales.
\end{abstract}

PALABRAS CLAVE: RENTA DEL SUELO URBANO. MERCADO INMOBILIARIO. PRODUCCION DE CIUDAD. POLIITICA URBANA NEOLIBERAL.

\section{Reorientation of big capital towards real estate}

\begin{abstract}
Why real state production, which was a relatively minor branch of capital accumulation, lagging behind in technical and organizational terms, in recent times has become a very important investment option for big capital? In a stage of weakness in profit rates and scarcity of profitable businesses, what is the appeal of real estate for large investors? In Latin America, where this activity had a limited national scope, even at regional or
\end{abstract}


local level, suddenly massive multinational capitals arriving by financial means or in the form of direct investment are being seen: how do they get a sufficient remuneration to explain this mutation? This text aims to shed light on this subject on the hypothesis that this is accomplished in the urban land market through speculation. An expression usually imprecise, with very diverse and sometimes contradictory meanings. Based on the Marxist Theory of Urban Land Rent developed by the author, the key category to examine these operations is that of inductive speculation, which does not have the appearance of speculation, but in which investors are betting on combining the proper capitalist profit itself with the capture of significant increases in the price of urban land. In these transactions, the large size of capital accumulation is decisive along with the support of the State, which is functional to neoliberal urban policies.

KEYWORDS: URBAN LAND RENT. REAL-ESTATE MARKET. PRODUCTION OF THE CITY. NEOLIBERAL URBAN POLICY.

PALAVRAS-CHAVE: ALUGUEL DE TERRA URBANA. MERCADO IMOBILIÁRIO. PRODUÇÃO DA CIDADE. POLIITICA URBANA NEOLIBERAL.

\section{Introducción}

En las últimas décadas el sector de producción de espacio construido ha experimentado mutaciones de gran envergadura, tanto a nivel mundial como en nuestra región latinoamericana. Hasta hace poco tiempo esta era una rama claramente secundaria entre las distintas esferas de acumulación de capital, con un grado de concentración modesto y un avance técnico limitado. En nuestra región predominaba el capital doméstico, con poca presencia de inversionistas internacionales y las principales empresas tenían un ámbito de actuación limitado a una ciudad o una región. Hoy, sin embargo, presenciamos un verdadero volcamiento del gran capital hacia el sector inmobiliario. La concentración de capital ha dado un salto abrupto y hoy vemos en la rama capitales de enorme magnitud. En los portafolios de los grandes conglomerados económicos la promoción inmobiliaria ya es un rubro de mucho peso. Pero, además, el capital inmobiliario se ha internacionalizado produciendo una verdadera avalancha de capital transnacional en nuestros países, bajo distintas modalidades.

Estas transformaciones se dan en una etapa en la que la tasa de ganancia general a nivel internacional desfallece y hay una escasez de oportunidades rentables de inversión. ¿No es esperable que también en la rama de la edificación la rentabilidad sea baja? ¿Qué es lo que atrae a los grandes capitalistas hacia lo inmobiliario en una época de precariedad en la rentabilidad?

Nuestra intuición al respecto consiste en lo siguiente: aunque efectivamente es probable que también en la rama de la edificación la tasa de ganancia predominante sea estrecha, existen opciones de inversión muy redituables que solo están al alcance de grandes capitales. Algunas de ellas han emergido a partir de políticas estatales de corte neoliberal que hacen que el Estado cree opciones de inversión en el sector a través de privatizaciones que permiten que los grandes capitales reemplacen a los organismos estatales en muchas operaciones, con el apoyo y el concurso estatal. Pero especialmente, la rama de lo inmobiliario presenta un rasgo que le es peculiar y que permite a los grandes capitales hacer negocios muy atractivos. Se trata de la renta del suelo urbano: los movimientos de los precios del suelo en las ciudades y en especial la emergencia de ciertas modalidades de especulación, ofrecen al gran capital oportunidades de réditos 
Reorientación del gran capital hacia lo inmobiliario...

SAMUEL JARAMILLO

jugosos. Pero cuando se habla de especulación, y de especulación urbana, con frecuencia se utilizan acepciones del término muy difusas, a veces con contenidos contradictorios. Lo que nos proponemos en este texto es precisar los rasgos específicos que asume este mecanismo, para tener una visión más precisa de su operación y ayudar a entender cómo se articula este dispositivo a las políticas urbanas neoliberales de los últimos tiempos.

Además de esta introducción, el texto tiene dos secciones iniciales que abordan de manera sucinta dos temas relacionados. Uno: las características estructurales del sector de producción-circulación de espacio construido que han explicado el tradicional relegamiento relativo del sector inmobiliario en la inversión del gran capital. Dos: algunas anotaciones sobre el debilitamiento en la tasa de ganancia y las estrategias que suscita entre los capitales para la mitigación de sus efectos. Para analizar la operación del mercado inmobiliario y del suelo urbano que es pertinente para el tema que nos ocupa, utilizaremos como referencia, en la siguiente sección, la Teoría Marxista de la Renta del Suelo Urbano que he ido desarrollando en las últimas décadas. Una sección ulterior intenta enlazar el análisis teórico más abstracto con algunos rasgos de las políticas urbanas neoliberales en el continente que darían alguna luz sobre este fenómeno de la irrupción del gran capital en el sector. Finalmente presentamos una sección muy breve de conclusiones.

\section{Las peculiaridades de la rama de producción de espacio construido}

Desde mediados de los años setenta del siglo XX, en la tradición del análisis urbano marxista, se hicieron avances importantes para explicar el desarrollo limitado de las relaciones capitalistas en la rama de la producción de espacio construido, particularmente en la producción de vivienda. Lo que se conoció como la Sociología Urbana Francesa, con el notable liderazgo de Christian Topalov $(1973,1984)$ y, de otro lado, la llamada Escuela de las Formas de Producción de Vivienda en América Latina (Jaramillo, 1981; Pradilla,1987; Schteingart, 1989; Lovera,1988, 2011; De Queiroz Ribeiro 1997; Pírez, 2016) llegaron a conclusiones convergentes al respecto.

Una de las dificultades que enfrenta el capital en esta rama es su largo período de rotación. La producción de un complejo edilicio de un cierto tamaño puede abarcar dos o tres años, un tiempo adicional debe agregársele en labores de concepción, diseño y obtención de permisos, y algo más de tiempo dedicado a la circulación y ventas. Para obtener una ganancia normal los bienes inmobiliarios deben venderse por una cantidad de valor mucho mayor que el trabajo que ha sido incorporado estrictamente en su producción, lo que agrava los serios problemas de solvencia que tiene el sector por otras razones.

El espacio construido es un bien durable y cristaliza una gran cantidad de valor, para no hablar de sobreprecios adicionales como el que mencionamos antes, y otros más. Los bienes que podría realizar esta industria se reducirían enormemente si sus productos tuvieran que venderse al contado. Se requieren dispositivos que fraccionen y difieran estos pagos. Uno de ellos es el alquiler. Tiene el inconveniente de que eleva el monto de los pagos, pues el intermediario cobra una ganancia no solo por la fracción de valor desgastada en el consumo, sino por el monto del precio del inmueble que permanece 
inmovilizado. La venta a plazos a través de préstamos hipotecarios, alternativa que se ha generalizado con la consolidación del capital de préstamo, y que con frecuencia recibe subsidios estatales, también eleva el precio para el consumidor. El capital productivo de la rama es especialmente dependiente de este capital de préstamo, fuera de cuyo concurso prácticamente no puede funcionar.

Este rasgo de la rama le genera al capital frecuentes y profundas fluctuaciones. Las condiciones de realización son muy oscilantes. La disponibilidad de capital de circulación varía mucho, y cuando existen perspectivas de contracción, la compra de inmuebles es uno de los primeros consumos que se recorta. El largo período de rotación de capital tiende agravar este asunto. Las circunstancias del momento de decisión y comienzo de la producción suelen ser muy dispares a las predominantes cuando se sale a vender. Con un período largo de rotación hay más posibilidades de que un estrechamiento de la realización sorprenda al inversionista en medio del período productivo, y esto mismo retrasa su reacción. Un capitalista con rotaciones más ágiles puede responder prontamente a un deterioro en sus perspectivas de ventas: un promotor inmobiliario con frecuencia debe seguir invirtiendo para tener un producto terminado vendible, y esto profundiza las crisis de sobreproducción.

Para amortiguar los efectos de contracciones frecuentes y severas, los inversionistas del sector procuran reducir el peso del capital fijo, pero esto implica renunciar a importantes ventajas productivas ligadas a la mecanización. La proporción de trabajadores contratados con respecto a un monto determinado de inversión es especialmente elevada en este sector. La atomización de sub-mercados que tienen diversos ritmos de actividad conduce a los promotores a distribuir su capital en diversas opciones para reducir riesgos, pero sacrificando eventuales economías de escala. Se afirma entonces que la rama de producción de espacio construido evidencia un notable atraso técnico.

Esta rama utiliza tierra y los promotores capitalistas pagan una renta por acceder a ella. Su impacto sobre la expansión de las relaciones capitalistas es ambivalente. Los inversionistas compran los terrenos, lo que implica que tienen que contar con un monto adicional de capital inicial. Cuando el mercado opera normalmente no se debe pensar que esto sea una deducción de la ganancia del inversionista inmobiliario: esto es compatible con su obtención de la ganancia media. La renta es una sobreganancia cuyo pago lo hace el capitalista anticipadamente. Pero este sobreprecio sí afecta la solvencia de sus clientes, pues eleva el precio que el comprador debe abonar por el inmueble.

Otra fuente de perturbación para el inversionista es la dificultad de obtener un flujo de terrenos con las condiciones y precios adecuados para mantener un ritmo continuo de acumulación. La provisión de los mismos se convierte en una tarea muy importante y problemática en estos negocios. No obstante, la conexión con el mercado del suelo permite a estos inversionistas capturar incrementos en los precios del suelo, lo que les permite eventualmente hacer ganancias importantes. En fases embrionarias del desarrollo capitalista en la rama, el capital originario es con frecuencia amasado en operaciones ligadas a la "valorización" de terrenos. Esta noción es la que intentamos desarrollar para la etapa actual: la combinación de beneficios productivos y ganancias especulativas permite, eventualmente, rentabilidades atractivas en el contexto de una tasa de ganancia media muy débil. 
Reorientación del gran capital hacia lo inmobiliario...

SAMUEL JARAMILLO

La combinación de estos rasgos desemboca en lo que hemos anunciado: una rama de producción de espacio construido atrasada técnicamente, con importantes sobreprecios en sus productos, con baja concentración de capital y que en general debe limitarse a cubrir solo la parte más elevada de la demanda potencial. Con frecuencia debe compartir el espacio con formas no capitalistas de producción, algo sumamente acentuado en nuestros países, y concomitante con esto, persiste en todos los países capitalistas una grave precariedad habitacional.

\section{El estrechamiento de la tasa de ganancia media}

La tendencia a la contracción que exhibe de manera reiterada la tasa de ganancia media en el capitalismo es uno de los temas más debatidos, particularmente en la tradición marxista. No siempre es fácil de distinguir entre una tendencia descendente de largo plazo y estructural, y movimientos cíclicos de caídas y recuperaciones muy dolorosas y que son también características de este orden social.

En la formulación original del propio Marx en El Capital (1867/1975) de este asunto señala cómo la innovación técnica más generalizada, que implica un aumento de la composición orgánica de capital, termina por contraer la magnitud de la tasa de ganancia media. Los capitalistas individuales, buscando su propio beneficio, introducen técnicas que son más eficientes que las de sus competidores, lo que en el corto plazo les genera ganancias extraordinarias. Las innovaciones más frecuentes, ligadas a la maquinización, implican una disminución de la proporción de trabajo vivo en el valor del producto. Cuando la innovación se generaliza, esta proporción menor de trabajo vivo implicará también una baja proporcional del capital variable en el capital total. Como el capital variable es el único que produce plusvalía, también la plusvalía tendrá una proporción más baja con respecto al capital total. Esto no es otra cosa que una baja en la tasa de ganancia.

Más recientemente autores marxistas contemporáneos (Moseley,1991; Shaik, 2016) señalan otra fuente de este descenso en la tasa de ganancia, muy visible en la fase actual del capitalismo: la proliferación de actividades capitalistas que no generan plusvalía y que obtienen su remuneración de la captura de valor excedente generado en las ramas propiamente productivas de plusvalor. El desmesurado incremento en los gastos de mercadeo y publicidad, y la proliferación de intermediarios bursátiles y financieros implican que el excedente total se tenga que repartir entre un número cada vez mayor de capitales productivos e improductivos, haciendo caer la tasa de ganancia.

Marx plantea otra contradicción del capitalismo que tiene el mismo efecto. A través del tiempo, los asalariados reproducen su fuerza de trabajo en magnitudes similares, o no necesariamente crecientes. En cambio, los capitalistas, por su misma naturaleza y por la competencia entre ellos, tienden a acumular su capital y a reinvertir parte de sus ganancias. Los dos mecanismos solo pueden operar simultáneamente si existen mercados para realizar la producción más allá del consumo obrero: los mercados de consumo de lujo de las capas más afluentes, y eventualmente mercados externos. Pero esto tiene límites: se produce cada vez más, pero los trabajadores, que finalmente constituyen la parte masiva del mercado, no pueden ampliar su consumo en la misma proporción, lo que desemboca en una crisis de sobreproducción. Los capitalistas encuentran 
Reorientación del gran capital hacia lo inmobiliario...

SAMUEL JARAMILLO

dificultades cada vez más serias para realizar sus productos y para asegurar sus ventas deben reducir los precios, por lo tanto, sus beneficios y la tasa de ganancia se contrae.

Estos mecanismos se combinan históricamente y se articulan a otros fenómenos, adquiriendo peculiaridades que exigen análisis más específicos. Podemos delinear sucintamente algunos rasgos del pasaje de la etapa fordista/keynesiana de acumulación a la actual fase neoliberal y sus relaciones con este fenómeno de la contracción de la tasa general de ganancia.

La relativa estabilidad y crecimiento continuo que tuvo el sistema capitalista mundial desde la Postguerra hasta comienzo de los años setenta fue debilitándose a medida que algunos de sus soportes se erosionaron. El aumento en la productividad basado en la industria taylorista, que permitía que simultáneamente los capitalistas aumentaran sus ganancias en valor y los trabajadores tuvieran incrementos sostenidos en la cantidad de bienes que obtenían por su salario, comenzó a resquebrajarse por los límites que este tipo de organización técnica implica para los trabajadores: tareas rutinarias y repetitivas, vida cotidiana centrada en el consumo creciente y direccionado. La ampliación de la escala de producción ligada a la acumulación y el avance técnico en transporte y comunicaciones desbordó los límites de los estados nacionales que permitían una serie de regulaciones entre agentes que preservaban un cierto límite a la desigualdad, junto a dispositivos monetarios y macroeconómicos que amortiguaban la inestabilidad inherente a la competencia capitalista. Estos acuerdos se tornaron imposibles de mantener en el nivel del Estado-nación, y no pudieron ser reemplazados en el plano global en el que las instituciones estatales son, si mucho, embrionarias. La mengua en la rentabilidad global condujo al colapso de este orden fordista que fue reemplazado por un nuevo esquema comandado por las políticas neoliberales.

Este nuevo régimen se consolidó tanto por acciones colectivas de la clase capitalista, a través del aparato político y administrativo, como de acciones individuales de empresas capitalistas que buscaban oportunidades de negocios rentables. Un gran viraje en la política económica consistió en debilitar la participación estatal, tanto en su acción económica directa como regulatoria. Entre las novedades destaca el desmonte de las garantías laborales de los trabajadores, lo que se tradujo en una monumental contención salarial. Las grandes empresas deslocalizaron buena parte de sus tareas productivas a países de la periferia, en los cuales podían pagar salarios aún más bajos, y en las metrópolis ampliaron la automatización y la robótica. Si bien esto permitió aumentar la rentabilidad inicialmente, su margen de acción es limitado. La agudización de la desigualdad conduce a que la producción se concentre en franjas de mercado de lujo que dan muestras reiteradas de saturación y en intentos de ampliar el consumo masivo por la vía de la manipulación mediática y propagandística. Pero el resultado cada vez más generalizado es el de mercados copados con muy pocas perspectivas de ampliación.

El debilitamiento de la regulación estatal ha permitido, además de una escandalosa acentuación de la desigualdad, la expansión sin precedentes de estos capitales ficticios, particularmente financieros y bursátiles que copan una porción decisiva del excedente. Sin embargo, con la exacerbación de la competencia, y la autonomía regulatoria que han conquistado, desencadenan agudos episodios de crisis monetarias y crediticias que han vuelto a ser una amenaza para la continuidad de la acumulación capitalista. 
Reorientación del gran capital hacia lo inmobiliario...

SAMUEL JARAMILLO

\section{La renta del suelo urbano}

\section{Fuentes y manifestaciones}

Desde la óptica marxista (y ricardiana) el precio de los terrenos tiene una naturaleza diferente al precio de las mercancías normales. En estas últimas el precio es una cristalización del trabajo social que es necesario movilizar para su producción. Pero la tierra no es producida por el trabajo: el precio del suelo es la capitalización de rentas periódicas, una porción del excedente que el propietario de la tierra disputa a los inversionistas capitalistas en virtud del mecanismo del intercambio mercantil y la competencia.

Mientras que las rentas que surgen en el ámbito rural están asociadas a la rama productiva de la agricultura, el caso de las rentas urbanas es más complejo: los productos, los inmuebles, permanecen ligados a la tierra más allá del período de producción y esta conexión se extiende a su proceso de circulación y de consumo. En la ciudad se generan así dos familias de rentas: las rentas primarias, ligadas al proceso productivo de la construcción, y las rentas secundarias, que emergen en el proceso de consumo y circulación de los inmuebles (Jaramillo, 2009).

Entre las primeras se pueden distinguir las siguientes: la renta primaria diferencial tipo I, que está asociada a las diferencias en constructibilidad de los distintos terrenos, es decir, los diversos costos que enfrenta el productor en virtud de características físicomorfológicas de los lotes (inclinación, capacidad portante, etcétera). También alimenta esta renta la distancia desigual a las redes matrices de valores de uso colectivo en forma de red, como servicios públicos domiciliarios y vialidad, que deben ser provistos por los constructores. Estos últimos procuran acceder a las ventajas que ofrecen los mejores terrenos con respecto a esos factores, lo que les permite en principio disfrutar de menores costos y obtener ganancias extraordinarias. Pero, dado que la ventaja surge de características del suelo, el propietario de este está en capacidad, mediante la competencia entre los constructores, de apoderarse de esta ganancia excepcional en forma de renta.

Otra modalidad de renta primaria urbana es la denominada renta primaria diferencial tipo II, que está relacionada con la diversa cantidad de capital aplicado a la tierra, que en este caso está ligada a la técnica de construcción en altura. Las rentas urbanas primarias y las rentas rurales implican costos diferentes en cada lote, pero un precio uniforme del producto. En las rentas secundarias los precios de los inmuebles varían en cada lugar en función de la magnitud de las rentas: cuando las rentas crecen, crecen también los precios del espacio construido. Pero al mismo tiempo, la producción en altura implica que a medida que se eleva el número de niveles con los que se construye el costo unitario es cada vez mayor: una misma cantidad de espacio construido es mucho más costosa de producir en un rascacielos que en inmuebles de una sola planta. La interacción entre estas dos variables desemboca en un patrón bien conocido en las ciudades: para un nivel modesto en el precio de venta del espacio construido prevalece una densidad constructiva débil y un precio del suelo bajo. Para ciertos niveles intermedios en el precio del espacio construido prevalece una densidad constructiva más elevada y un nivel más alto del precio del suelo. El costo unitario de construcción no aumenta de manera gradual con el número de niveles, sino que hay saltos importantes cuando se traspasan ciertos umbrales. Esto determina que haya ciertas zonas con densidades constructivas y precios del suelo de 
Reorientación del gran capital hacia lo inmobiliario...

determinado rango, luego un escalón en que las densidades constructivas se agrupan en un cierto nivel mayor y con un precio del suelo más alto, y así sucesivamente. Aunque existe una asociación entre magnitud del precio del suelo y la altura de los edificios, no se trata de que una de estas variables sea la "causa" de la otra, sino que ambas magnitudes son el resultado de la interacción de las variables ya aludidas, el costo de producir espacio construido según la cantidad de niveles, y la magnitud del precio del espacio construido en cada lugar de la ciudad. Esta renta es uno de los determinantes de variación más importantes del precio del suelo en las ciudades.

La renta absoluta urbana es aquella que soportan los terrenos menos favorecidos de toda la ciudad para los diversos usos urbanos y que tienen los precios del suelo más bajos de la aglomeración. Aunque estos precios deben ser más elevados que los de sus usos no urbanos, generalmente su magnitud experimenta un salto y son mucho más elevados que los de los lotes contiguos rurales. La magnitud mínima de esta renta resulta de la relación de fuerzas entre oferentes y demandantes de terrenos urbanos y es muy significativa porque está presente en el conjunto de los predios de la ciudad, como el colchón básico sobre el que se estructuran todas las otras rentas: influye, por lo tanto, en el nivel de precios del suelo de toda la urbe. Su monto tiende a ser más alto en las ciudades más grandes, en aquellas que crecen con mayor celeridad, y en las que tienen alguna limitación natural para la disposición de tierras. Y en una circunstancia inesperada: allí donde por la penuria fiscal existen limitaciones en la dotación en infraestructura y escasean las tierras urbanas equipadas.

Las rentas secundarias están ligadas a los principales usos del espacio construido urbano. Una muy importante, es la que está conectada con la actividad comercial: la renta diferencial de comercio. No todos los terrenos ofrecen las mismas facilidades para ejercer esta actividad. En algunos de ellos hay un flujo de compradores mayor que en otros. Los comerciantes que se localizan en los mejores terrenos pueden disfrutar de una velocidad de circulación de su capital comercial superior a la de sus competidores. Con los mismos costos pueden obtener una tasa de ganancia comercial excepcionalmente elevada. Pero el mayor flujo de compradores que está en la base de este fenómeno no se debe a las virtudes de los comerciantes mismos, sino que es el resultado de una convención global de los ciudadanos que identifican estos lugares como los más apropiados para esta función. Existen algunas condiciones técnicas para esta elección, pero se trata de una convención que en cierta medida es arbitraria. Los propietarios de los terrenos con mejores condiciones tienen la posibilidad de exigir como renta toda la ganancia extraordinaria que en primera instancia obtienen los comerciantes que operan en ellos.

Alrededor del uso del espacio construido como vivienda se forman dos tipos de rentas secundarias que tienen distinta naturaleza, pero que se entrelazan. La renta diferencial de vivienda se desprende del hecho de que la vivienda es un valor de uso que requiere de la conexión espacial con otros inmuebles complementarios, como los lugares de trabajo, de aprovisionamiento, de educación, etcétera. Los terrenos de la ciudad no tienen un acceso homogéneo a estos lugares complementarios, y por lo tanto su enlace espacial implica para el usuario costos de distinta magnitud tanto monetarios como de tiempo. La competencia le permite al propietario territorial capturar lo que se ahorran los usuarios de vivienda que quieran localizarse en los lugares más favorables. 
La renta de segregación, también ligada a la vivienda, está asociada a la distribución desigual en el espacio de los distintos grupos sociales de acuerdo con sus ingresos. La separación en el espacio de los residentes de distinto poder económico en las ciudades capitalistas es una pauta ligada a un rasgo muy profundo de este orden social. En las sociedades anteriores al capitalismo el excedente se extraía por mecanismos muy evidentes, lo que exigía que en la superestructura jurídico-política existiera una clara diferenciación estamental entre las clases sociales. En contraste, en el capitalismo el excedente lo perciben los capitalistas a través de un mecanismo impersonal, el mercado, y en especial el mercado de la fuerza de trabajo, un dispositivo abstracto que hace opaca la existencia misma de la explotación. No es necesaria la distinción jurídica de clases, lo que es muy conveniente en términos de legitimación: todos los individuos son iguales ante la ley. Pero este principio no elimina la existencia real de clases sociales y de una jerarquía social muy pronunciada. Para efectos prácticos se introducen mecanismos ad hoc para hacer explícito el lugar de cada individuo en la escala social. El más importante es el gasto conspicuo: la diferencia entre dos integrantes de la clase capitalista es la magnitud de su acumulación. El gasto conspicuo se ejerce, más que para satisfacer una necesidad corriente, para mostrar que se tiene la suficiente acumulación para acometer ese gasto. Aquel que no pueda incurrir en él evidencia que su acumulación no es suficiente y que ocupa un lugar inferior en la jerarquía social. Esta pauta se extiende al conjunto de la población de tal manera que el monto del ingreso es la señal del lugar que se ocupa en esta gradación.

La localización residencial juega un papel similar. Si los grupos más adinerados se aglutinan en una determinada área, un individuo que resida allí obtiene el reconocimiento de que pertenece a esta élite. Para que esto sea efectivo se requiere de un dispositivo de exclusión: un sobreprecio de los inmuebles que están dispuestos a pagar los residentes por gozar de este reconocimiento. Quienes tienen un ingreso débil no están en condiciones de hacer este pago extra. Esto se convierte en renta porque también la distribución espacial de estas pautas es resultado de una convención colectiva: no basta que un millonario se asiente en un barrio popular para que este adquiera la virtualidad de ser un espacio positivamente connotado. Esto se configura a través de una convención colectiva que no controla nadie de manera individual y unilateral. Así, los constructores de inmuebles en los terrenos que gozan de esta distinción tendrían en principio una ganancia excepcional, pues con costos de construcción similares podrían vender en ese lugar sus productos con precios superiores a los compatibles con una ganancia media. Los propietarios territoriales que tienen el control jurídico de estos lotes privilegiados están en capacidad, mediante la competencia, de capturar toda la ganancia extraordinaria derivada de este mecanismo. Esta renta de segregación es uno de los mayores factores de diferenciación cuantitativa de los precios del suelo urbano.

También existe una renta secundaria industrial. Paradójicamente, su importancia es menor. La proliferación de medios de transporte y de comunicación tienden a homogeneizar el espacio urbano en términos de las condiciones de producción de mercancías. Los industriales son agentes poderosos, pero consumen mucho espacio y las diferencias de costos de localización son bajos: tienden a ocupar lugares residuales y esta renta tiene una magnitud baja, salvo circunstancias excepcionales ligadas a la regulación urbana.

Estas diversas rentas, que tienen periodicidades muy diferentes, se entrelazan y se homogeneizan con su capitalización en un precio del suelo para cada lote. Cada terreno soporta simultáneamente varias rentas, que alimentan precisamente su precio. 
Existen dos tipos de entrelazamiento: las rentas primarias son aditivas entre sí y con las rentas secundarias. Un lote que tiene ventajas comerciales y además facilidades constructivas porta una renta comercial y una renta primaria diferencial que se agregan para alimentar su precio. Pero las rentas secundarias son substitutivas entre sí. Un terreno puede ser usado como vivienda o como local comercial. En él están presentes tanto una renta de vivienda como una renta de comercio. Pero estas dos rentas secundarias se substituyen: solo se manifiesta en el mercado la que sea mayor, y esto induce a que lo que prevalezca en ese lugar sea precisamente la actividad que corresponde a la renta de mayor magnitud.

\section{Agentes y transacciones en la producción-circulación de espacio construido}

Los agentes y las transacciones que se establecen entre ellos en el marco urbano tienen diferencias significativas respecto del rural. En este último el esquema más claro y extendido pone en relación dos agentes: el propietario de la tierra y el inversionista agrícola. El primero le cede al segundo por un tiempo limitado el uso de la tierra de su propiedad, mientras que el inversionista agrícola le paga al propietario una renta periódica. Esta transacción es un alquiler. La propiedad territorial la ejerce una clase estable que recibe la renta de manera reiterada y que no pierde por ello la propiedad del suelo. Es factible que el inversionista agrícola compre la tierra: en este caso le paga al propietario original la renta en su forma capitalizada, lo que no altera en lo fundamental esta relación: el inversionista paga por ejercer simultáneamente el papel de propietario territorial y capitalista agrario.

Arrendar un lote urbano para construirlo, mientras el terrateniente original conserva su propiedad, es algo problemático. Lo que se generaliza es que el propietario vende el terreno al inversionista de la construcción, cediendo de manera definitiva su dominio sobre el lote a cambio del precio del suelo. Además, el producto de esta actividad constructiva, el inmueble, sigue ligado a la tierra más allá de concluido el proceso productivo. Surge entonces un nuevo agente: el usuario final. Para que él pueda disfrutar del valor de uso de este bien es muy difícil que pague solamente por el espacio construido: debe abonarle al constructor el precio total del inmueble, que incluye el precio del suelo. Nótese la diferencia que existe con el caso rural: el consumidor final de los bienes agrícolas no debe comprar el terreno donde estos productos fueron cultivados. En este sentido, el precio de un bien normal tiende a tener dos componentes: el capital más la ganancia. En contraste, el precio de un bien agrícola consta del capital, la ganancia más la renta; finalmente, el precio de un bien inmueble incluye el capital, la ganancia capitalista, la renta periódica (por el tiempo de construcción) y el precio del suelo.

La configuración que surge es muy distinta a la del caso rural: la propiedad del suelo no es ejercida por un agente de manera estable e indefinida, sino de manera sucesiva en el tiempo por agentes con muy diversas características. En un esquema simplificado, se empieza por un propietario de tierra no construida, usualmente rural. Este propietario, que calificamos como "original", vende este terreno a un segundo agente, que provisionalmente denominamos "constructor", a cambio de un precio que anticipa las rentas urbanas que soportará el lote. Pero en este acto el propietario original se desprende de su propiedad y sale del circuito de producción y circulación del espacio construido, mientras que el constructor deviene en propietario del terreno por un tiempo limitado, 
el correspondiente al período de producción y venta del inmueble. Finalizado este, el constructor vende el inmueble al usuario final: el precio de esta edificación incluye tanto el espacio construido como el suelo urbano. En ese momento el constructor deja de ser propietario de tierra urbana y en cambio el usuario comienza a serlo, ya que su propiedad del inmueble supone también la propiedad del lote en el que está asentada la edificación.

Este último agente tiene una gran diversidad interna: puede ser un industrial, un comerciante o alguien que utiliza la edificación como vivienda para su propia reproducción. Dentro de estas categorías hay también gran diferenciación: en la vivienda el usuario final puede pertenecer a distintas clases sociales, y también puede haber desde grandes superficies comerciales hasta bodegueros y tenderos de barrio, desde enormes fábricas, hasta artesanos. Y esto sin contar los distintos intermediarios que deben agregársele a este esquema simplificado: muchos de quienes compran inmuebles no lo hace para su uso personal, sino para alquilarlo a un inquilino, quien sería el usuario final. Existen también intermediarios tanto en el mercado de compra de tierras como de edificaciones.

Destacamos entonces las siguientes implicaciones. La propiedad territorial urbana no es ejercida de manera fija por un agente. No es tan fácil identificar, como en el caso rural, a un agente que sea la "encarnación" de la propiedad territorial: en cada momento la propiedad jurídica es ejercida por agentes sucesivos, que se disputan entre sí la captación de las rentas. En un momento determinado, bajo una misma relación de propiedad jurídica, encontramos agentes de muy distinta naturaleza. A diferencia de la tierra agrícola, cuya propiedad tiende a concentrarse, en el medio urbano hay una gran dispersión y una tendencia a la fragmentación: sobre todo en el caso de la vivienda, los medios de financiación contemporáneos promueven que se difunda el acceso a la propiedad, multiplicando el número de propietarios de las parcelas en los que se asientan. Esto es importante porque en casos en los que la construcción de inmuebles se hace a través de la renovación urbana, quienes operan como "propietarios originales" son los dueños de uso de estos inmuebles. Esta opción es cada vez más importante en las ciudades contemporáneas y fuente de tensión: estas propiedades son muy fragmentadas y al promotor por renovación esto le representa un obstáculo para obtener el suelo para sus operaciones.

Esta volatilidad y fluidez en la propiedad determina entonces que en la pugna por la apropiación de las rentas sean especialmente relevantes los cambios en el tiempo de los precios del suelo urbano, que trataremos a continuación.

\section{Los movimientos en los precios del suelo}

Se pueden distinguir tres tipos diferentes de movimientos en los precios del suelo urbano que se entrelazan en sus manifestaciones concretas. El primero, los movimientos estructurales generales. Sus determinantes están asociados a la estructura socioespacial de la ciudad o a su estructura económica y afectan al conjunto de los terrenos de la urbe. Su resultado más notable es una tendencia general creciente de los precios del suelo, presente en casi todas las ciudades capitalistas.

Algunos factores que están en la base de este fenómeno: aun si el precio del suelo conserva en el tiempo una misma magnitud en valor, dado que la innovación técnica hace 
Reorientación del gran capital hacia lo inmobiliario...

SAMUEL JARAMILLO

bajar el precio de la inmensa mayoría de las mercancías verdaderas, crece el poder de compra de la renta (o el precio del suelo) en términos de estos otros bienes. Esto se interpreta como un aumento "real" en el precio del suelo. Si el precio del suelo es la capitalización de rentas periódicas, y estas se actualizan teniendo como referencia la tasa media de ganancia, si esta última disminuye, como parece ser la tendencia en el capitalismo, simétricamente el precio del suelo aumenta.

Otros factores empujan al alza a diversas rentas urbanas propiamente dichas: cuando las ciudades se expanden físicamente, aumenta la renta absoluta urbana. También lo hace la renta diferencial de vivienda. Como los precios del espacio construido también se elevan tendencialmente, un número mayor de terrenos superan los umbrales que determinan la viabilidad de producir en densidades constructivas mayores y por lo tanto con rentas superiores: la renta primaria diferencial tipo II crece.

Los movimientos coyunturales generales consisten en fluctuaciones cíclicas y coyunturales alrededor de esta tendencia de largo plazo. Afectan al conjunto de los terrenos de la ciudad. Como los terrenos no son producidos, las variaciones en su oferta no son significativas, por lo que estas oscilaciones responden en lo fundamental a fluctuaciones en la demanda de terrenos originadas en mercados ligados al mercado del suelo. Uno de ellos se asocia a la construcción, uno de los sectores de producción capitalista más oscilantes en su ritmo de actividad. Estas variaciones trasmiten expansiones y contracciones en la demanda por tierra urbana que hacen fluctuar su precio. Los inmuebles y los terrenos urbanos son también depósitos de valor, que conviven y compiten por el ahorro con otras opciones de colocación, como los papeles financieros y bursátiles. Los cambios coyunturales en estas alternativas hacen agudizarse o relajar la tensión del mercado por bienes inmobiliarios urbanos y hacen crecer y contraerse a los precios de la tierra en las ciudades.

Los movimientos estructurales particulares son específicos del medio urbano y tienen una gran relevancia para el tema que nos ocupa. Responden a fenómenos estructurales, no tienen carácter coyuntural y afectan en cada momento a una porción limitada de terrenos. Tienen que ver con cambios de uso del espacio construido. La dinámica espacial de una estructura urbana, que incluye tanto el simple crecimiento como mutaciones en su configuración socioespacial, determina que ciertos terrenos que en un momento tienen un uso predominante pasen a un uso diferente que soporta una renta superior a la original. El precio de esos terrenos tiene un incremento súbito, eventualmente muy considerable, en un período de tiempo relativamente limitado: zonas comerciales que se expanden e involucran terrenos que antes se dedicaban a la vivienda; áreas de vivienda habitadas por capas de ingresos modestos que pasan a ser ocupadas por residentes de ingresos superiores; terrenos rurales que pasan a ser urbanos.

Esto también sucede con respecto a la construcción en altura. Cuando el precio del espacio construido en su incremento paulatino supera un cierto umbral, se hace viable la construcción en una densidad mayor, lo cual genera un crecimiento acelerado del precio del suelo en un lapso corto. Examinándolo en la historia de un lote de terreno que experimenta esta mutación, tenemos una etapa inicial en la que el precio del suelo tiene un crecimiento pausado (la tendencia estructural al alza) con ciertas fluctuaciones; una segunda etapa de agudo crecimiento; $y$ una tercera en la que el precio, en un nivel más alto, retoma el crecimiento tendencial general con sus oscilaciones. 
SAMUEL JARAMILLO

\section{Las formas de la especulación}

Se conoce como especulación a la transacción mercantil que consiste en adquirir un bien en determinado precio y venderlo a un precio superior. En el caso del mercado de la tierra, y en general inmobiliario, se trata de capturar incrementos en los precios de la misma y de los inmuebles. Esta especulación urbana adquiere distintas modalidades que es conveniente diferenciar.

Existe una forma elemental que denomino protoespeculación. Como existe esta tendencia secular al crecimiento de los precios inmobiliarios, y estos bienes tienen una larga vida útil, su comprador no solamente tiene como referencia para la transacción el valor de uso del bien, sino la expectativa de evolución de su precio. La economía neoclásica habla de que los inmuebles son simultáneamente bienes de consumo y de inversión. No se trata de especuladores profesionales, pero estos propietarios buscan beneficiarse de los incrementos en el precio del suelo lo que condiciona, en buena medida, su comportamiento en este mercado.

Una segunda modalidad, la especulación pasiva que es la más evidente y considerada como la única, consiste en adquirir terrenos (o inmuebles) a un precio bajo, esperar a que este suba y vender más caro, sin que el agente modifique las características del bien. Esto puede tomar cuerpo alrededor de los movimientos coyunturales de los precios, pero como en general son volátiles e inesperados, estas acciones tienden a desarrollarse con relación a los movimientos estructurales particulares. Así, estos operadores intentan identificar los lugares y los tiempos en los que emergen estos incrementos súbitos.

El agente no influye en la emergencia de dichos incrementos, que tendrían lugar aun sin su concurso: lo que él busca es identificar en qué sitio y en qué momento tienen lugar. Para la rentabilidad de su operación, le conviene acertar en qué momento compra, ni antes de que comience el alza, pues significaría mantener su inversión improductiva durante un tiempo, ni después de que el aumento haya comenzado. Y lo mismo con el momento de venta: no debe vender antes de que el precio concluya su período de alza. Por consiguiente, se opera con una expectativa y no hay ninguna garantía de acertar con estas previsiones. Incluso existe la posibilidad de que el crecimiento esperado en el precio nunca se vuelva realidad y la operación especulativa fracase.

Para tener éxito en este tipo de transacciones de manera estable es indispensable contar con información, de dos tipos. Se deben conocer las prácticas urbanas de la ciudad. Normalmente se trata de un conocimiento intuitivo, pero es decisivo para juzgar qué mutaciones en la estructura socioespacial son viables y probables. También es crucial estar al corriente de las decisiones de otros agentes que afectan el precio del suelo: acciones de promotores tanto privados como estatales, inversiones en infraestructura que pueden alterar la configuración socioespacial, cambios en la regulación urbana, etcétera.

El acceso a esta información debe ser asimétrico. Debe ser privilegiado con respecto al eventual propietario previo. Si no es así, y el propietario está enterado de que las rentas del terreno se elevarán en un futuro próximo, podrá exigir un mayor precio de venta, aun si las rentas no han cambiado. Es lo que se conoce como precio de anticipación: el precio no solamente es la capitalizan las rentas actuales, sino que incluye las expectativas de rentas futuras de mayor magnitud. Si la información es plenamente accesible 
Reorientación del gran capital hacia lo inmobiliario...

SAMUEL JARAMILLO

al vendedor lo esperable es que el precio se eleve de tal manera que la ganancia del especulador se homologue a la ganancia media normal. Para que el especulador pueda obtener ganancias extraordinarias es crucial que cuente con información exclusiva: por ello se trata de un mercado muy opaco.

La información privilegiada es tan decisiva que surge una gran tentación por parte de estos agentes para intentar obtenerla trasgrediendo las normativas legales, por ejemplo, filtrando con anticipación los programas de acción gubernamental o los cambios regulatorios. Incluso estos agentes no siempre se limitan a estar enterados de tal o cual acción gubernamental, sino que procuran influir en ellas en su beneficio, con presiones políticas y económicas, a menudo ilegales. El "riesgo moral" es notable en un sector en el que la corrupción es muy frecuente.

La especulación pasiva tiene limitaciones en su expansión. Además de la opacidad y el riesgo moral, lo cierto es que es evidente que, aun operando dentro de la más estricta legalidad, se trata de operaciones improductivas, en las que se captura una porción de valor en cuya generación no ha contribuido el agente favorecido, lo que propicia que se atribuya a estas acciones un carácter parasitario. En muchos países existen fuertes medidas tributarias que castigan este tipo de ingresos y reducen su rentabilidad.

En parte por estas razones, se ha ido consolidando otra modalidad de especulación, que sin duda es la más extendida e importante hoy en día, y que está directamente ligada al interrogante que nos hacemos. La denominamos especulación inductiva y tiene dos características sobresalientes. La primera es que el agente no está sometido a la condición de tratar simplemente de adivinar en qué lugar y en qué momento se dan estos cambios abruptos en los precios del suelo. Si dispone de una capital importante que le permita emprender operaciones urbanísticas de gran magnitud, está en capacidad de determinar las coordenadas de estos eventos: no se limita a esperar su ocurrencia, sino que, dentro de ciertos límites, puede inducir y dirigir las mutaciones.

La segunda característica es que no tiene la apariencia de una operación especulativa, sino que parece una actividad productiva. El agente no compra terrenos en un momento para venderlos, idénticos, un tiempo más tarde. Compra lotes desnudos y vende edificaciones. Así que sus réditos parecen tener el mismo carácter que el de cualquier empresario productivo. Como veremos, lo substancial de las ganancias de estos promotores surge de la captura de incrementos en el precio del suelo.

La relativa autonomía de estos agentes para enrumbar y desencadenar los incrementos súbitos en el precio del suelo les permite debilitar la acción del propietario previo. De esta manera lo substancial de la eventual ganancia extraordinaria de las operaciones no pasa al terrateniente, sino que queda en los bolsillos de este especulador inductivo, quien eventualmente puede hacer negocios con una tasa de ganancia superior a la normal.

Ilustraré este mecanismo con la referencia a un caso desarrollado en mi ciudad. En la década de los años setenta del siglo XX, Bogotá exhibía un esquema de distribución socioespacial muy característico de las ciudades latinoamericanas de la época. Existía una nítida macro-segregación socioespacial en la que los grupos de altos ingresos se aglutinaban hacia el norte y los más pobres al sur. Las actividades comerciales y 
Reorientación del gran capital hacia lo inmobiliario...

SAMUEL JARAMILLO

terciarias superiores se desarrollaban en el centro tradicional de la ciudad y en algunos centros secundarios. Los establecimientos comerciales se alineaban a lo largo de las calles y crecían de manera paulatina y previsible en el tiempo.

Un promotor con gran capacidad de inversión emprendió una operación muy ambiciosa. Se propuso introducir la figura del mall que era prácticamente desconocida en la ciudad. La ofreció como una novedad inmobiliaria, de lujo y cosmopolita. Buscó terrenos que, en la pauta predominante hasta ese momento, no tenían una vocación comercial: hacia el norte, en lugares muy periféricos, que hasta el momento se estaba poblando con vivienda de ingresos medios. El precio del suelo era relativamente modesto, por el monto limitado de los ingresos de quienes comenzaban a ser sus residentes, y por la distancia al núcleo central de la ciudad. Compró mucha más tierra que la necesaria para edificar el centro comercial pues se proponía construir vivienda para altos ingresos en el entorno. No era la localización residencial predominante para las élites, pero se proponía aprestigiar esas localizaciones si el mall tenía éxito. Parte importante de su inversión la destinó a una agresiva campaña publicitaria encaminada a transformar las pautas de comportamiento de los eventuales compradores. Se trataba de convencer tanto a comerciantes como a usuarios que un mall, controlado y confinado, era una modalidad no solo más eficaz para estas actividades, sino que tenía una connotación de modernidad y de desarrollo. En esta época, los grupos de mayores ingresos era reticentes a aceptar los productos de los promotores capitalistas. Habían acumulado una tradición de proveerse de vivienda a través de la construcción por encargo, que permitía producir alojamientos personalizados a la medida de los gustos de cada cliente. Y se privilegiaban las casas individuales. Consecuentemente, la campaña apuntaba a convencerlos de la conveniencia de ocupar apartamentos de lujo en conjuntos cerrados de edificios en altura.

La operación fue muy exitosa. Los locales comerciales del mall se vendieron rápidamente y con los precios más altos del mercado. Los residentes de clase alta, venciendo la reticencia mencionada, compraron los apartamentos a precios muy elevados. Desde luego que no lució como una operación especulativa. Las ganancias obtenidas por el inversionista no parecen distinguirse de las que obtiene un inversionista propiamente productivo.

Sin embargo, existe una evidencia que puede hacer pensar de manera diferente. El inversionista adquirió tal cantidad de tierra, que sobrepasó su capacidad para edificarla en su totalidad en el plazo inmediato. Construyó una porción de ella en edificios de vivienda de clase alta, pero el resto decidió vendérselo a otros promotores como lotes vacíos. Esto permite hacer una comparación cuantitativa entre el precio de adquisición de esos terrenos y el precio con el cual pudo venderlos. El incremento es bien significativo: en un período de alrededor de cinco años, el precio de estos lotes se multiplicó, en términos reales, por un poco menos de siete veces.

Este incremento tan notable no se limita a los terrenos que se transaron vacíos, sino que se extiende a los lotes edificados por el inversionista: una parte muy considerable de las ganancias de este último no se le deben atribuir a un beneficio propiamente capitalista, sino al incremento en los precios del suelo. Esto explica que su rentabilidad haya sido superior a la media.

Aunque el promotor pueda percibir que estos aumentos en los precios del suelo fueron generados por su habilidad empresarial, ya que "valorizó" esos terrenos, habría que 
Reorientación del gran capital hacia lo inmobiliario...

SAMUEL JARAMILLO

decir que no lo hizo añadiendo valor a través de un proceso productivo: lo que hizo fue direccionar los incrementos en las rentas urbanas hacia los lugares y en los tiempos en que se dieron y cuyo control tenía este empresario. Sin su intervención hubieran ocurrido en otras latitudes.

Nótese que los propietarios originales de estos terrenos no pudieron beneficiarse de estas alzas tan notables en los precios. El promotor compró al precio predominante en este momento, y los vendedores no pudieron anticipar su incremento posterior. Si ellos hubieran aumentado anticipadamente su precio, el promotor hubiera considerado la opción de trasladar su operación a otro sitio.

\section{La especulación inductiva y las políticas urbanas neoliberales}

Muchas de las operaciones inmobiliarias realizadas por los grandes capitales del sector en nuestras ciudades actualmente responden al mecanismo de la especulación inducti$v a$, aunque sus manifestaciones no son idénticas. Para enlazar con la referencia teórica expuesta, los negocios que descansan sobre este mecanismo tienen en común dos características: son acciones que apuestan a trasgredir la estructura convencional de usos del suelo vigente en un momento determinado; y para hacer esto, el tamaño apreciable de acumulación de los operadores juega un papel determinante. Adicionalmente, en un número considerable de ellas, es necesario que el Estado entre a facilitar estos negocios.

Miremos las operaciones de renovación urbana, en las que se busca rescatar sectores de la ciudad que se consideran sometidos a procesos de decadencia física y social, mediante inversiones inmobiliarias que introduzcan usos más rentables y, eventualmente, mayores densidades constructivas. Frecuentemente estas zonas están ocupadas por residentes populares.

Aunque se podría pensar que el funcionamiento espontáneo del mercado inmobiliario debe garantizar la preeminencia de los usos que arrojen rentas mayores, esto es un poco más complejo. Si los terrenos están ya construidos y deben ser demolidos y reemplazados por edificaciones nuevas, suele suceder que los promotores deban pagar por ellos no solo por el terreno desnudo, sino el precio total del inmueble, aunque solo se lo vaya a aprovechar como lote. Con frecuencia eso implica un precio del suelo que es excesivamente alto, incompatible con una rentabilidad media en la operación de renovación. La propiedad jurídica de estas tierras suele ser muy fragmentada, lo cual dificulta enormemente la compra del suelo en las magnitudes requeridas para estas intervenciones. Agréguese que la misma eventualidad de estas operaciones tiende a ser advertida por los propietarios originales, y aunque ellos no tienen la capacidad de hacer las inversiones para propiciar los incrementos en los precios del suelo, sí pueden anticipar los precios futuros, lo cual eventualmente disuade a los grandes promotores de emprender estos negocios. Esto sin hablar de las movilizaciones de resistencia social y política de los pobladores contra estas acciones que los desplazan, cada vez más vastas y frecuentes. La renovación urbana masiva, apoyada exclusivamente en la operación pura del mercado inmobiliario, no es muy atractiva para el gran capital, salvo ciertas circunstancias poco frecuentes.

Pero estos proyectos, incluso aquellos que implican desplazamiento de pobladores, se tornan atractivos cuando existe el concurso de entidades gubernamentales que 
favorecen las operaciones por distintas vías. Varios mecanismos regulatorios del mercado del suelo tienen como propósito forzar a los poseedores a negociar sus inmuebles a bajos precios: plazos perentorios para desarrollar los lotes, expropiaciones expeditas, tasas e impuestos locales onerosos, e incluso crecientes. Con alguna frecuencia, oficinas gubernamentales se encargan de adquirir a bajo precio estas propiedades utilizando combinaciones de aquellas medidas, para luego vendérselas a los promotores privados a precios bajos, aunque, más frecuentemente, en figuras de asociación público-privada en las que el Estado aporta la tierra a precios de quema. Esta oferta de tierra barata por parte del Estado se da cuando el mismo gobierno es propietario jurídico de los terrenos, tratándose de lugares que tuvieron en el pasado un uso activo, pero que han caído en la obsolescencia: infraestructura ferroviaria y portuaria desafectada, antiguos mercados, mataderos, cuarteles, etcétera. De esta manera los promotores obtienen jugosas rentabilidades a partir de la elevación, a veces espectacular, de los precios del suelo, lo que se hace evidente a posteriori cuando estas operaciones culminan con éxito.

Los gobiernos justifican estos favores con distintos argumentos. Se señala que se ha reanimado a estas secciones degradadas de la ciudad, lo que no hubiera sido posible si la inversión tuviera que haber sido estatal. Que los organismos estatales incluso obtienen réditos porque se trataba de terrenos ociosos que no arrojaban ningún ingreso fiscal o, si lo hacían, era muy bajo. Incluso se argumenta que el crecimiento del precio de los inmuebles implica un alza en los recaudos de impuestos a la propiedad que compensan los generosos aportes de municipalidades y agencias inmobiliarias oficiales. En definitiva, los intrincados y a veces ingeniosos dispositivos financieros que se diseñan para justificar y hacer posible estas operaciones sustentadas por el Estado se apoyan en el mecanismo que hemos delineado: la especulación inductiva, que se muestra invisible como especulación.

La segregación confinada, esa forma de exclusión espacial que se apoya en barreras físicas, murallas, vigilantes, cámaras, que prolifera en nuestras ciudades y cuya expansión es atribuida al urbanismo neoliberal, no parece ser solamente un rasgo meramente cultural impuesto por este régimen: cumple una función importante en la rentabilidad de las operaciones inmobiliarias. Esta segregación amurallada le permite al promotor con fuerte capacidad de inversión, trasgredir la convención urbana vigente en un momento, adquirir los terrenos a un precio moderado y desarrollar el programa con un cambio radical en los usos del suelo, lo que implica un crecimiento importante en su precio.

Estas operaciones han tenido repercusiones en los esquemas socioespaciales de nuestras ciudades. El predominio hasta los años setenta del siglo XX de un modelo muy polarizado, con una sección bien definida ocupada por los grupos acomodados (el "cono de alta renta") y una vasta área residual ocupada homogéneamente por grupos populares, se ve erosionado por estos emprendimientos. Cuando comienza a haber una cierta concentración de capital en la promoción, los inversionistas más osados empiezan a comprar terrenos en esas áreas homogéneamente populares, con sus precios correspondientes, y a producir allí conjuntos cerrados destinados a usuarios de mayores ingresos a quienes se les vende con precios del suelo implícitos más elevados. Algo aceptable para estos últimos compradores, en la medida que se tenga una determinada masa crítica, y que la separación funcional sea efectiva. Una consecuencia de ello es que la nítida dicotomía socioespacial tiende a debilitarse. Ya las zonas populares no son tan homogéneamente ocupadas por pobres, porque proliferan estas islas de programas de 
Reorientación del gran capital hacia lo inmobiliario...

SAMUEL JARAMILLO

clase media, e incluso, de clase alta. La macrosegregación disminuye su intensidad. Pero, en revancha, aumenta la microsegregación. La vecindad de grupos de niveles de ingreso muy diverso y de formas de vida a veces contrapuesta, acentúan las tensiones entre vecinos y refuerzan las prácticas excluyentes de separación física. Pese a ello, sobre todo cuando estos programas son pioneros, ofrecen a los promotores pingües ganancias asociadas a esta especulación inductiva.

Los grandes programas de vivienda social introducidos por las políticas habitacionales liberales, que liquidaron a los promotores gubernamentales y los substituyeron por subsidios a la demanda para que las viviendas sociales fueran producidas por promotores privados, son otra opción importante para estas operaciones de especulación inductiva. Estos programas son hechos a la medida de las grandes compañías promotoras privadas, a las cuales el Estado favorece por distintas vías: ampliación de su demanda solvente mediante los subsidios directos al comprador -que es su rasgo más visible-, pero también alivios fiscales de diverso tipo, garantías de estabilidad en sus operaciones, magnitud considerable de los programas para favorecer economías de escala, subsidios financieros visibles y encubiertos o adecuación de la regulación urbana a las formas de operación del oferente. A ello se suma, el tamaño cada vez más exiguo de las viviendas, uniformidad de diseño, flexibilización de exigencias de provisión de infraestructura urbana y servicios complementarios, etcétera.

Entre las condiciones de privilegio que se les otorga a estos grandes capitales se destaca el hecho de que no se les requiere ninguna localización determinada, y se deja esto a su elección en el juego libre del mercado del suelo. Como consecuencia, estos promotores buscan los terrenos más baratos, que son localidades extremadamente periféricas, a menudo a decenas de kilómetros de la aglomeración urbana. Se configuran así conglomerados en los que se concentra la pobreza, aislados y remotos, discriminados y estigmatizados, verdaderos guetos inducidos por la política oficial, y que en el urbanismo internacional se consideran una práctica nefasta ya superada. Pero parte de la rentabilidad de estos programas se desprende precisamente de la amplísima flexibilidad en la localización, que permite a los promotores buscar terrenos alejados, de los que sus propietarios originales no pueden esperar desarrollos espontáneos en períodos de tiempo próximos y por ello están dispuestos a venderlos a precios bajísimos, con frecuencia basándose en referencias a rentas rurales de magnitud muy limitada. Cuando estos programas son ocupados, pueden constatarse alzas muy considerables en los precios, que han nutrido los réditos de los desarrolladores.

En complejos empresariales de alta gama y comercio de lujo, los precios del espacio construido alcanzan niveles altísimos, lo que hace factible construir con elevados índices constructivos -rascacielos-. Teóricamente esto llevaría consigo la elevación muy pronunciada de los precios del suelo, si hubiera una gran competencia entre promotores que produjeran en estas técnicas de gran altura: la ganancia extraordinaria ulterior, eventualmente derivada, iría a parar al propietario territorial. Pero si los promotores que pueden realizar estas construcciones en gran altura son escasos, los pocos inversionistas que tienen esta capacidad de construcción pueden presionar con éxito a los vendedores de terrenos en esos lugares a que vendan con precios más bajos. De esta manera, el gran capital concentrado puede conservar como ganancia extraordinaria una parte del excedente que no se convierte en renta y esto le permite obtener una ganancia excepcional, superior a la media. 
Esta figura ha dado paso a un nuevo "producto inmobiliario": la gran torre multiusos donde se combinan varias actividades en los distintos niveles del edificio. Los pisos más bajos se destinan a actividades comerciales y de entretenimiento (tiendas, restaurantes, cines, bares); los niveles siguientes a hotelería; los siguientes a oficinas, y los más elevados a vivienda. Con ello se aprovechan al máximo todas las rentas potenciales. La magnitud apreciable de capital requerido para estas operaciones, y la importancia que adquiere la experiencia y habilidad para llevarlas adelante, las hace muy atractivas para el gran capital.

\section{A manera de conclusiones}

El sector de la producción inmobiliaria ofrece al gran capital oportunidades de inversiones redituables, en esta fase de contracción de la tasa general de ganancia, a través de operaciones en las que los inversionistas combinan la ganancia propiamente capitalista con la captura de incrementos en los precios del suelo. Se trata, por lo tanto, de operaciones que involucran la especulación. Pero de una modalidad especial: la especulación inductiva. En ella el gran capital no tiene que esperar la emergencia espontánea de los movimientos estructurales particulares del suelo urbano, ligados a ciertos cambios de uso y de mutaciones en la edificabilidad económica de algunos terrenos, sino que con su capacidad de inversión pueden dirigirlos de tal manera que sus rasgos espaciales y temporales les permitan capturar estos incrementos, con frecuencia muy pronunciados.

Estas operaciones no tienen la apariencia de especulación, porque estrictamente no existe una transacción inicial de compra de suelo con precios bajos para más tarde vender los mismos terrenos a un precio más elevado. En la especulación inductiva se compran terrenos vacíos (u ocupados con edificaciones de poco valor y precios del suelo bajos) y se venden inmuebles con destinaciones o densidades constructivas diferentes a las iniciales, con precios totales de la edificación mucho más elevados. La totalidad de la diferencia en valor parece ser creada por la acción productiva de los inversionistas. Pero esta inversión lo que hace es dirigir los incrementos en los precios del suelo hacia las áreas intervenidas por los inversionistas. Esto puede constatarse comparando los precios del suelo iniciales con los precios del suelo implícitos después de la operación, lo que se consigue con técnicas de valoración inmobiliaria o a veces directamente con transacciones sobre algunos terrenos que se transan desnudos, pero en un contexto urbano que ha variado con la intervención inmobiliaria.

En estas operaciones el grado de la acumulación del gran capital es algo decisivo, pues le permite reescribir porciones substantivas del tejido socioespacial urbano, lo cual exige una importante magnitud en la intervención. Algo similar ocurre con los precios del suelo elevados que pueden alcanzarse solamente a través de una densidad constructiva muy alta, que solo puede ser obtenida por el gran capital y no está al alcance de competidores con acumulación más modesta. La excepcionalidad de este grado de acumulación debilita además a los propietarios originales de los terrenos que difícilmente pueden disputar los incrementos en los precios del suelo urbano a través del mecanismo de los precios de anticipación.

Sin embargo, en muchas operaciones de este tipo la magnitud de la acumulación del gran capital no es suficiente y requiere de acciones gubernamentales que las hagan 
Reorientación del gran capital hacia lo inmobiliario...

SAMUEL JARAMILLO

posibles. Se trata de la base de prácticas que identificamos como ligadas al urbanismo neoliberal: dispositivos desarrollados para quebrar la resistencia de propietarios originales del suelo y obligarlos a vender a precios bajos; flexibilización de las normas urbanísticas que facilitan estas operaciones favoreciendo los intereses de grandes promotores; asociaciones público-privadas en las que el Estado ofrece terrenos de su propiedad a precios bajísimos, entre otros. 


\section{Q Bibliografía}

》De Queiroz Ribeiro, L.C. (1997). Dos Cortiços aos condomínios fechados. As formas de Produção da Moradia na Cidade do Rio de Janeiro. Río de Janeiro: Civilização Brasileira.

» Jaramillo, S. (1981) Producción de vivienda y capitalismo dependiente: el caso de Bogotá. Bogotá: Universidad de los Andes.

» Jaramillo, S. (2009). Hacia una teoría de la renta del suelo urbano. Segunda edición revisada y ampliada. Bogotá: Ediciones Uniandes.

»Lovera, A. (1988). La Forma Heterogénea de Desarrollo Tecnológico de la Construcción. Tecnología y Construcción, 4(1), IDEC, FAU, UCV, Caracas, 1988

»Lovera, A. (2011). Radiografía de la industria de la construcción. El ciclo del capital. Caracas: Universidad Central de Venezuela, Ediciones de la Biblioteca.

» Marx, K.I. (1867/1975). El Capital. Critica a la Economía Política. Buenos Aires: Siglo XXI.

》Moseley, F. (1991). The falling rate of profit in the postwar United States. Londres: Palgrave Macmillan.

»Pírez, P. (2016). Las heterogéneas formas de producción y consumo de la urbanización latinoamericana. Quid 16, 6, 131-167.

》Pradilla, E. (1987). Capital, Estado y vivienda en América Latina. México DF: Fontamara.

»Schteingart, M. (1989). Los productores del espacio habitable. México DF: El Colegio de México.

"Shaik, A. (2016). Capitalism. Competition, Conflict, Crises. Oxford: Oxford University Press.

» Topalov, C. (1973). Capital et Propriété foncière. París: CSU.

» Topalov, C. (1984). Ganancias y rentas urbanas: elementos teóricos. Madrid: Siglo XXI.

Samuel Jaramillo / ejaramil@uniandes.edu.co

Economista, Universidad de los Andes. Bogotá. Doctor en Urbanismo Universidad de Paris XII. Profesor Titular, Facultad de Economía Universidad de los Andes. Investigador del Centro de Estudios de Desarrollo Económico. Ha escrito varios libros y artículos sobre urbanización latinoamericana, vivienda, renta del suelo urbano, mercado inmobiliario, servicios públicos y transporte. 